\title{
Documentation of Phosphine Resistance in Red Flour Beetle, Tribolium castaneum Herbst (Tenebrionidae, Coleoptera) and Rice Weevil, Sitophilus oryzae Linn (Curculionidae, Coleoptera) in Tamil Nadu, India
}

\author{
P. Yasodha ${ }^{1 *}$, M. Karpagam ${ }^{1}$, P. Senthil ${ }^{2}$, C. Gailce Leo Justin ${ }^{1}$, \\ P. Masilamani ${ }^{1}$ and S. Mohankumar ${ }^{3}$
}

${ }^{1}$ Anbil Dharmalingam Agricultural College and Research Institute, Navalur Kuttapattu, Trichy, Inida

${ }^{2}$ Urumu Dhanalakshmi College, Trichy, India

${ }^{3}$ Department of Plant Molecular Biology and Biotechnology, Tamil Nadu Agricultural

University, Coimbatore, Inida

*Corresponding author

\section{A B S T R A C T}

Keywords

Tamil Nadu,

Warehouse, Storage pests, Phosphine

resistance,

Documentation

Article Info

Accepted:

12 January 2019

Available Online:

10 February 2019
Survey were conducted to collect storage pests such as red flour beetle, Tribolium castaneum and rice weevil, Sitophilus oryzae from twenty three different government storage warehouses of the Tamil Nadu. Phosphine resistance in $T$. castaneum ranged from 91.67 to 100 per cent while in $S$. oryzae ranged from 66.67 to 90 per cent. About 91.67 per cent of maximum phosphine resistance was recorded in Nagarkoil, TNCSC. Considering S. oryzae, highest resistance level (90\%) was recorded in Trichy, TNCSC while Pudukkottai, TNCSC showed lowest resistance level (66.67\%). Improper sealing with sub-lethal dosage of phosphine leads to phosphine resistance. Poor sanitation made the few resistant population to breed with susceptible population to develop heterogenous population over the period leading to development of resistance.

\section{Introduction}

Annually, India produces around $210 \mathrm{Mt}$ of food grains, among which 30 per cent is going to the central pool maintained for public distribution / export (Semple, 1992). Annual post harvest losses resulting from insect damages, microbial deterioration and other factors are estimated to be from 10 to 25 per cent of worldwide production (Mathews, 1993). Among these post harvest losses, three per cent of quantity and quality deterioration is caused by storage pests (Hill, 1990). Coleopteran, Lepidopteran orders including mites are encountered as major pests of stored products. More than 600 species of beetles and 70 species of moths among the insects and 335 species of mites (Rajendran, 2002) 
were found as stored pests. Major stored pests of cereal grains in India includes rice weevil, Sitophilus oryzae (L), red flour beetle, Tribolium castaneum (Herbst), lesser grain borer, Rhyzopertha dominica (F), warehouse moth, Ephestia cautella (Walker) and psocids (Liposcelis spp) (Rajendran, 1994).

Among these pests, particularly, S. oryzae and T. castaneum are the major insect pests which cause a pungent, bad odour in the grain and contaminate the food with dead bodies and waste products (Zettler, 1974). Attempts have been made to get completely manage stored grains from insect pests by insecticide application. Phosphine has been a worldwide used fumigant for the management of stored insects for almost seven decades (Price and Mills, 1988; Chaudhry, 2000). Today we relay on phosphine fumigant because of its low cost, fast diffusion and absence of residues within confined area (Chaudhry, 2000). But, still frequent application and long term usage of this single fumigant within confine area, improper sealing causing sublethal dosage increases the risk of resistance development in resistance population. Therefore, phoshine resistance in $T$. castaneum and rice weevil, $S$. oryzae collected from different godowns of Tamil Nadu were documented.

\section{Materials and Methods}

A commercial $56 \%$ (F) formulation of Aluminium phosphide (Quickphos), provided by United Phosphorous Ltd was used to document resistance of phosphine among populations. Infested grains containing adult red flour beetle and rice weevil were collected from twenty three different storage godowns viz. Coimbatore, Thiruchirappalli, Thanjavur, Thiruvarur, Chennai, Virudhunagar, Madurai, Erode, Pudukkottai, Thoothukudi, Sivagangai, Ramanathapuram, Perambalur, Namakkal, Karur, Ariyalur, Dindigul, Theni and
Nagerkoil of Tamil Nadu (Table 1) during January to August 2014. About 200-400 adult beetles and weevils were collected from each warehouse. Insects were collected in polythene bag with their food media (whole and broken wheat) providing aeration and carried to the laboratory of the Department of Agricultural Processing Engineering of Agricultural Engineering College \& Research Institute, Tamil Nadu Agricultural University at Trichy. Rice weevil was reared in the laboratory using rice grains and wheat flour was utilized to rear red flour beetle. About $250 \mathrm{~g}$ of food media placed in plastic jar $(10 \mathrm{X}$ $15 \mathrm{~cm}$ ) and 100-200 insects were then release in each jar for feeding and oviposition. The jar was placed in a rearing cage $(30 \times 30 \mathrm{~cm})$. The temperature and relative humidity were maintained at $30 \pm 2{ }^{\circ} \mathrm{C}$ and $70 \pm 5 \%$ respectively. After a month, homogenous population was taken and used for bioassay.

Bioassay was conducted by exposing the test insects to discriminative dose (DD) of phosphine as per the method recommended by FAO. DD value of phosphine is common $(0.04 \mathrm{mg} / \mathrm{L})$ for both $S$. oryzae and $T$. castaneum. The adults of these insects collected from different locations were exposed to DD to assess the level of phosphine resistance following the method suggested by Sinha et al., (2008) and FAO (1975). Stock solution of phosphine was prepared by dispensing $3 \mathrm{~g}$ of aluminium phosphide tablet in a phosphine chamber (FAO Model, 1975). Air tightness is a prerequisite to maintain the gas concentration. Hence, proper care was taken to tighten the nozzles in the chamber. Desiccator was used as a fumigation chamber to maintain working solution (Discriminative dose). Within the desiccators, insects were confined in $20 \mathrm{ml}$ test tubes covered with gadda cloth. Discriminative dose of phosphine gas were injected into desiccators with micro-syringe through rubber septum fitted to a socket in the 
desiccator's lid. Proper care was taken to prove that there is no leakage. Observation was taken after $24 \mathrm{~h}$ to record the resistance level. Ten replications were maintained for both the tested insects.

\section{Results and Discussion}

The screening test using discriminative dose of phosphine $0.04 \mathrm{mg} / \mathrm{L}$ for both $T$. castaneum and $S$. oryzae by FAO method to characterize the insecticide resistance collected from different warehouses of Tamil Nadu showed that the mortality at the discriminative dose varied significantly among population collected from twenty three different storage warehouses of Tamil Nadu. (Table 1).

Phosphine gas is a promising fumigant for the management of stored grain pests and the occurrence of phosphine resistance in stored pest population is a challenges due to the continued effective use of this fumigant universally. The use of discriminative dose for quick and early detection of phosphine resistance in wild population of stored products insect is a valuable tool, because DD concentration is expected to kill all susceptible population. The number of insects surviving at the discriminative dose in a population sample will indicate the degree of resistant individuals. Red flour beetle showed intense phosphine resistance than rice weevil. At the given DD, 100 per cent resistance was observed almost all the population collected from different warehouses except population collected from Nagarkoil (SWC) with 91.67 $\%$ in $T$. castaneum. Totally, 23 samples of $S$. oryzae collected from warehouses, invariably almost all population showed more than $65 \%$ of phosphine resistance. Among these $S$. oryzae population collected from Trichy, SWC showed 90 per cent resistance and population collected from Nagerkoil, SWC showed 66.67 per cent phosphine resistance
(Graph 1). Tamil Nadu Civil Supplies Corporation (TNCSC) showed more phosphine resistance compared to other warehouses. Since, TNCSC is not having proper sanitation, the chances of breeding of resistant population among the susceptible population is high.

The level of phosphine resistance level is in the order of TNCSC $>$ SWC $>$ CWC $>$ FCI. Comparatively minimum resistance level was noticed among CWC, FWC and SWC. High resistance levels suggest that these populations have been under high selection pressure for many years (Benhalima et al., 2004) in a closed condition. Fragoso et al., (2003) suggested that the movement of insects due to the trading of susceptible commodities may be one the important possible and probable factor for the spreading of insecticide resistance at world level. The physiological mechanism of phosphine resistance is not completely elucidated. However, phosphine resistance has been associated with the active exclusion of phosphine by the gas exchange system (Price, 1981, 1984; Chaudhry and Price, 1990). This resistance mechanism is based on the excretion of poisonous compounds by the organism also through the active exclusion of the gas through the respiratory system, associated with the reduction in the inhalation of the phosphine gas (Price, 1984) (Fig. 1).

The lack of proper airtight conditions for fumigation with leaky structures increases the frequency of failures in the management of stored pests and thus increases the degree of phosphine resistance. Hueth and Regev (1974) described the process by which an insecticide, in this model fumigation with phosphine, selects for resistance and a new population with increased resistance remains. Their model considered a single pest with a single level of resistance. Schlipalius et al., (2008) identified four different resistance 
levels relative to the pests being susceptible. Phosphine fumigation is a single method followed for a longer period to manage stored product insects, but its continuous and indiscriminate use has resulted in the evolution of resistant populations. Repeated application of phosphine in poorly sealed warehouse with sub-lethal dose of phosphine results in of the development of strong resistance among both pests.
Resistance to phosphine has already been repeated in many countries of Asia and Africa. Pimentel et al., (2006) indicated that phosphine resistance in $T$. castaneum was associated with a lowered respiration rate. The production of $\mathrm{CO}_{2}$ reduces with the increase of the resistance level indicating that the reduction of the respiration rate of the resistant strains leads to reduced uptake of the fumigant by the resistant insects.

Table.1 Phosphine resistance on red flour beetle and rice weevil collected from warehouses of Tamil Nadu

\begin{tabular}{|c|c|c|c|c|}
\hline S.No & $\begin{array}{l}\text { Name of the } \\
\text { warehouse / location }\end{array}$ & Collection date & T. castaneum & S. oryzae \\
\hline \multicolumn{5}{|c|}{ Food Corporation of India } \\
\hline 1 & Coimbatore & January, 2014 & $100.0 \pm 0.00(89.40)$ & $81.67 \pm 5.04(64.65)$ \\
\hline \multicolumn{5}{|c|}{ Central warehouse corporation } \\
\hline 2 & Thiruchirappalli & January, 2014 & $100.00 \pm 0.00(89.40)$ & $78.33 \pm 5.36(62.25)$ \\
\hline 3 & Thanjavur & January, 2014 & $100.00 \pm 0.00(89.40)$ & $78.33 \pm 5.36(62.25)$ \\
\hline 4 & Thiruvarur & February, 2014 & $100.00 \pm 0.00(89.40)$ & $81.67 \pm 5.04(64.65)$ \\
\hline 5 & Chennai & February, 2014 & $100.00 \pm 0.00(89.40)$ & $78.33 \pm 5.36(62.25)$ \\
\hline 6 & Virudhunagar & March, 2014 & $100.00 \pm 0.00(89.40)$ & $85.00 \pm 4.65(67.21)$ \\
\hline 7 & Madurai & March, 2014 & $100.00 \pm 0.00(89.40)$ & $76.60 \pm 5.51(61.07)$ \\
\hline 8 & Erode & March, 2014 & $100.00 \pm 0.00(89.40)$ & $85.00 \pm 4.65(67.21)$ \\
\hline \multicolumn{5}{|c|}{ State warehouse corporation } \\
\hline 9 & Thiruchirappalli, & April, 2015 & $100.00 \pm 0.00(89.40)$ & $90.00 \pm 3.91(71.56)$ \\
\hline 10 & Pudukkottai, & April, 2015 & $100.00 \pm 0.00(89.40)$ & $81.67 \pm 5.04(64.65)$ \\
\hline 11 & Thiruchirappalli, & April, 2 & $100.00 \pm 0.00(89.40)$ & $93.33 \pm 3.25(75.03)$ \\
\hline 12 & Madurai, & April, 2015 & $100.00 \pm 0.00(89.40)$ & $91.67 \pm 3.60(73.22)$ \\
\hline 13 & Thoothukudi, & May, 2014 & $100.00 \pm 0.00(89.40)$ & $85.00 \pm 4.65(67.21)$ \\
\hline 14 & Thirunelveli, & May, 2014 & $100.00 \pm 0.00(89.40)$ & $81.67 \pm 5.04(64.65)$ \\
\hline 15 & Sivagangai, & May, 2014 & $100.00 \pm 0.00(89.40)$ & $78.33 \pm 5.36(62.25)$ \\
\hline 16 & Ramanathapuram, & June, 2014 & $100.00 \pm 0.00(89.40)$ & $86.67 \pm 4.43(68.58)$ \\
\hline 17 & Perambalur, & June, 2014 & $100.00 \pm 0.00(89.40)$ & $81.67 \pm 5.04(64.65)$ \\
\hline 18 & Namakkal, & June, 2014 & $100.00 \pm 0.00(89.40)$ & $85.00 \pm 4.65(67.21)$ \\
\hline 19 & Karur, & July, 2014 & $100.00 \pm 0.00(89.40)$ & $81.67 \pm 5.04(64.65)$ \\
\hline 20 & Ariyalur, & July, 2014 & $100.00 \pm 0.00(89.40)$ & $85.00 \pm 4.65(67.21)$ \\
\hline 21 & Dindigul, & August, 2014 & $98.33 \pm 1.67(82.57)$ & $86.67 \pm 4.43(68.58)$ \\
\hline 22 & Theni, & August, 2014 & $100.00 \pm 0.00(89.40)$ & $86.67 \pm 4.43(68.58)$ \\
\hline 23 & Nagerkoil, & August, 2014 & $98.33 \pm 1.67(82.57)$ & $75.00 \pm 5.64(60.00)$ \\
\hline
\end{tabular}

Per cent Resistance \pm SE, $n=23$; Figures in parentheses are arc-sine transformed values; 
Fig.1 Level of Phosphine resistance in T. castaneum and S. oryzae collected from different parts of Tamil Nadu

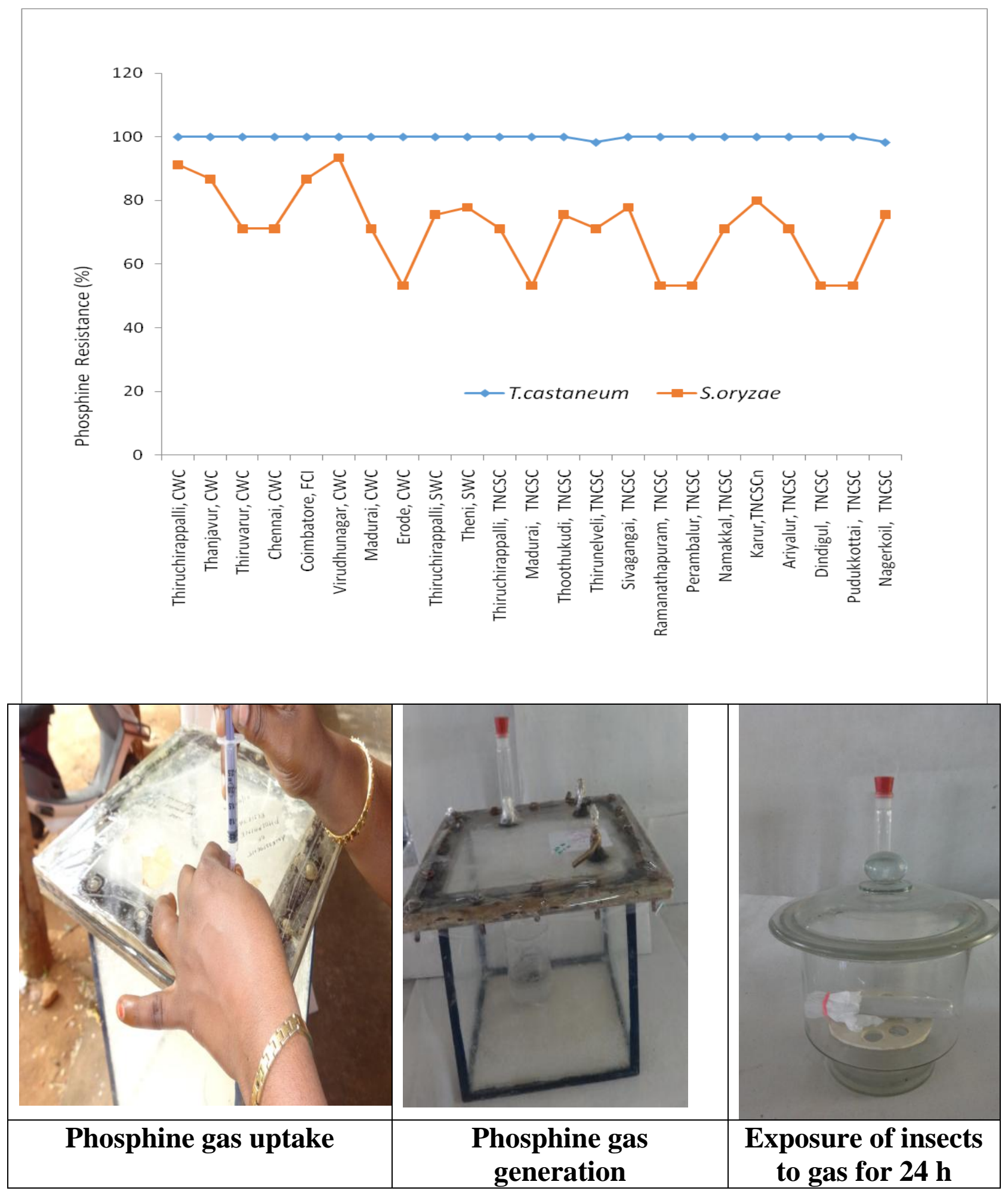


Maintenance of susceptible population of rice weevil and red flour beetle for 25 generations from 2010 onwards

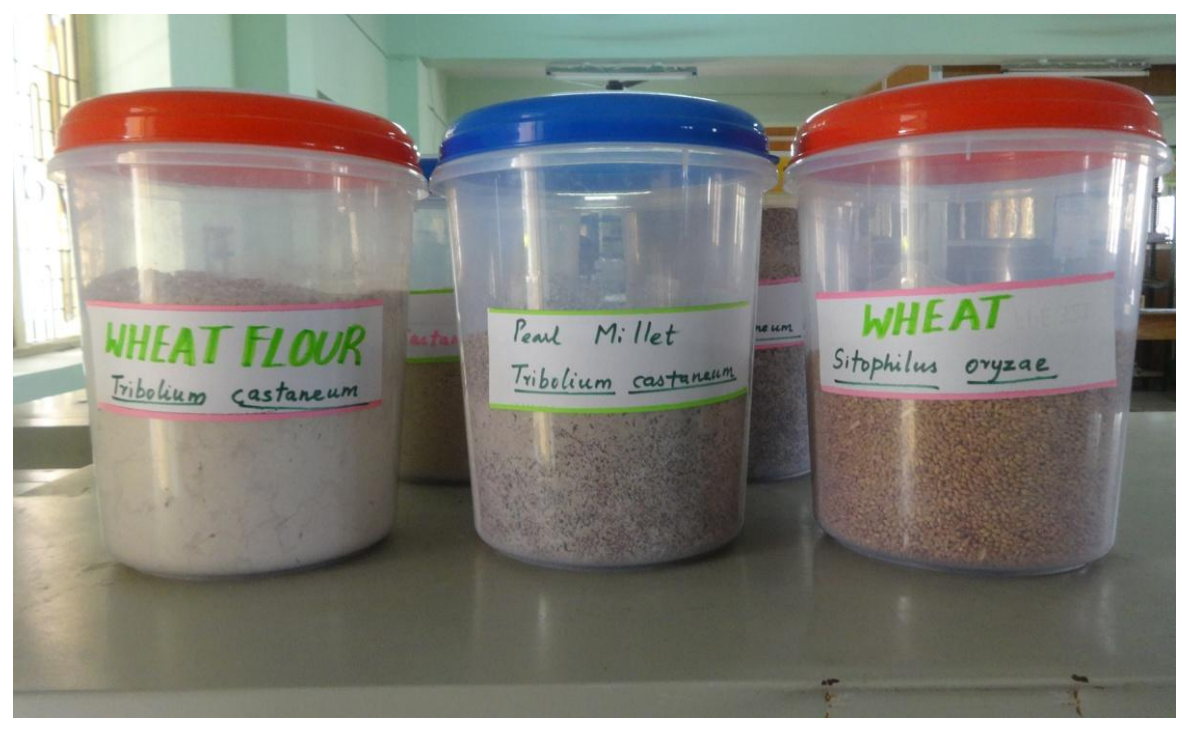

Maintenance of homogeneous resistant population
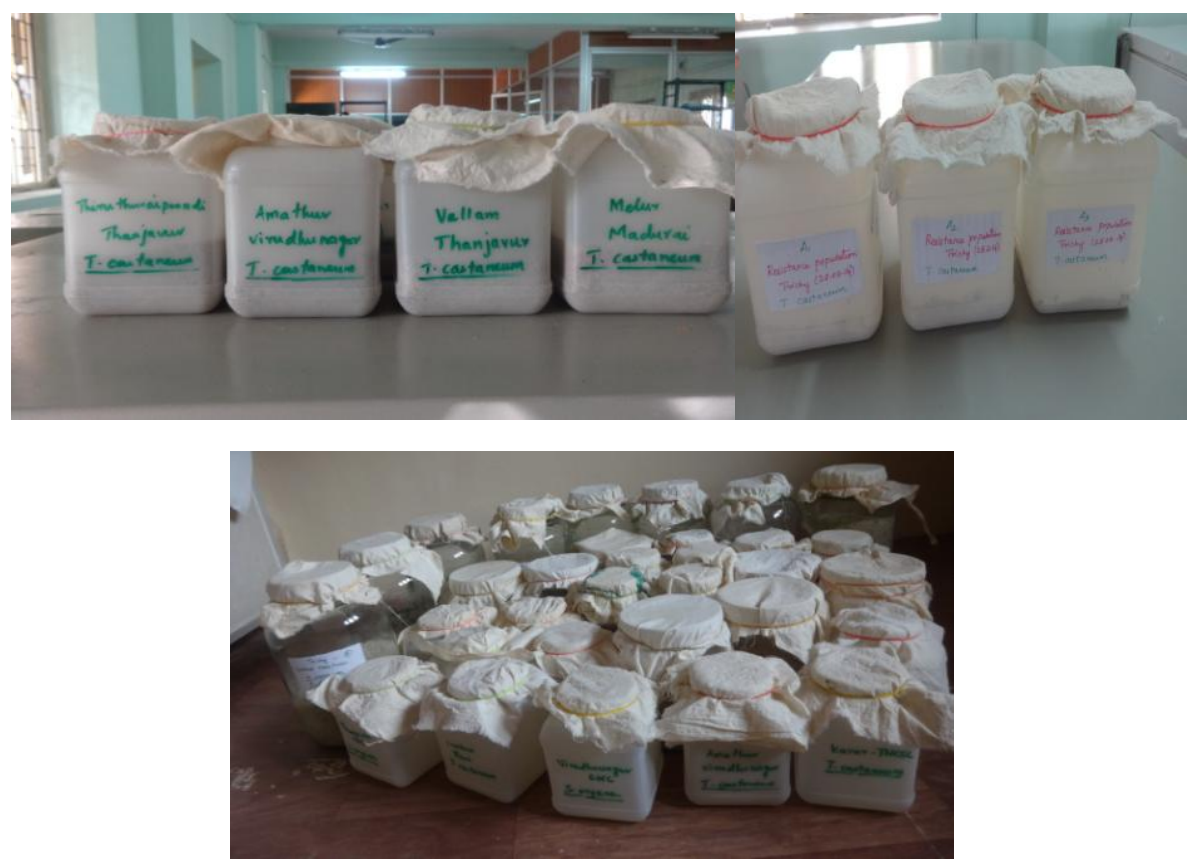
When compared to population collected from storage godown of Tamil Nadu. But in storage godown population that is resistance population has most tolerant to phosphine resistance at hours after treatment. When compared with the control population, most of the treated populations had higher resistance levels. This could involve development of adequate educational programs for rice post harvest systems and adequate demonstration of IPM principles and practices in on-farm and commercial storage facilities (Cuperus et al., 1993).

The primary cause of the development of resistance is the use of standard fumigation techniques, in particular the leakiness of the warehouses that leads to sub lethal doses. Gas leaks not only for the mud plastered doors and ventilators but also through the porous walls. Current fumigation practices require high standards of sealing and dosing. The problem can largely be circumvented by enclosing the grain stacks in polythene sheets. Tyler et al., (1983) and Taylor (1989) have suggested increased fumigation exposure periods to assure complete insect mortality. Since fumigation under gas proof polythene sheets permits the retention of gas for long period, this technique of stacked fumigation should be preferred over the usual practice of total warehouse fumigation. Among warehouses, even though the commodity is not infested with pests, if humidity exceeds by one percent also, fumigation is followed. This is also one of the reasons for development of resistance. Since, Tamil Nadu is favoured with high temperature, this also paves for insecticide resistance.

\section{Acknowledgement}

We would like to acknowledge the Science and Engineering Research Board, New Delhi for funding this project. The Dean, Agricultural Engineering College and
Research Institute, Kumulur, Trichy is acknowledged for supporting the work with laboratory facility.

\section{References}

Alleoni, B. and Ferreira, W. 2006. Control of Sitophilus zeamais Mots and Sitophilus oryzae weevils (Coleoptera, Curculionidae) in stored wheat (Triticum aestivum L.) with insecticide pirimiphos methyl (Actellic 500 ce). 9th International Working Conference on Stored Product Protection, 1242PS10$18-6193$.

Baloch, U.K. 1992. Integrated Pest Management in Food Grains. Food and Agriculture Organization of the United Nations and Pakistan Agricultural Research Council, Islamabad, Pakistan. pp. 117.

Benhalima H, Chaudhry M Q, Mills K A, Price N R. 2004. Phosphine resistance in stored-product insects collected from various grain storage facilities in Morocco. J Stored Prod Res 40: 241249.

Chaudhry, M.Q., 2000. Phosphine resistance: a growing threat to an ideal fumigant, Pesticide Outlook, pp:88-91

FAO Method No. 16, 1975. Recommended methods for the detection and measurement of resistance of agricultural pests to pesticides. Tentative method for adults of somemajor pest species of stored cereals, with methyl bromide and phosphine. Plant Protection Bulletin FAO, 23 (1):12-25.

Hill, D.S. 1990. Pests of stored products and their control, pp. 89-251. Belhaven Press.

Semple, R.L., Hicks, P.A. Lozare, J.V. and Castermans, A.. 1992. Towards Integrated Commodity and Pest Management in Grain Storage. Rome: 
Food and Agriculture Organization, May.

Hueth, D. D. and Regev, U.U. 1974. "Optimal Agricultural Pest Management with Increasing Pest Resistance." American Journal of Agricultural Economics 56(3): 543-552.

Matthews, G.A. 1993. Insecticide application in stores. In: Matthews GA, Hislop EC (Eds) Application Technology for Crop Protection. CAB International, Wallingford, UK pp 305-315.

Price, N.R. 1981. A comparison of the uptake and metabolism of 32P-radiolabelled phosphine in susceptible and resistant strains of the Lesser Grain Borer (Rhyzopertha dominica). Comparative Biochemistry and Physiology 69C, 129131.

Price, N.R., Dance, S.J., 1983. Some biochemical aspects of phosphine action and resistance in three species of stored product beetles. Comparative Biochemistry and Physiology 76, 277281.

Price, N.R., 1984. Active exclusion of Rhyzopertha dominica (F.) (Coleoptera: Bostrichidae). Journal of Stored Products Research 20, 163-168.

Rajendran S. 2002. Pesticide Spraying in Kerala - Human Cost and Environmental Loss, Economic and Political Weekly, XXXVII(23)2206-7.
Rajendran, S. 1994. Responses of phosphine resistance strains of two stored-product insect pests to changing concentrations of phosphine. Pestic. Sci., 40:183-186

Schlipalius, D. I., Chen, W.W. Collins, P.J. Nguyen, T.T. Reilly P.B. and Ebert P.R. 2008. "Gene Interactions Constrain the Course of Evolution of Phosphine Resistance in the Lesser Grain Borer, Rhyzopertha dominica." Heredity 100(5): 506-516.

Sinha, S.N., Singh S.N., and Srivatsava. C. 2008. Effect of smoke on Rhyzopertha dominica and Callusobruchus maculatus mortality and its susceptibility to phosphine. In: Donahaye, E.J. Navarro, S. and Leesch, J.G. [Eds.] (2001. Proc. Int. Conf. Controlled Atmosphere and Fumigation in stored Products, Fresno, CA.29 Oct. - 3 Nov, 2000, Executive Printing Services, Clovis, CA, USA. pp.431-437. Zakladnoi, G.A and Ratanova, V.F.. 1987. Stored Grain Pest and their Control. Oxonian Press Pvt., Ltd., New Dehli. pp. 268.

Zettler, J.L. and Cuperus, G.W. 1990. Pesticide resistance in Tribolium castaneum (Coleoptera: Tenebrionidae) and Rhyzopertha dominica (Coleoptera: Bostrichidae) in wheat. J. Econ. Ent., 83: 1677-1681.

\section{How to cite this article:}

Yasodha, P., M. Karpagam, P. Senthil, C. Gailce Leo Justin, P. Masilamani and Mohankumar, S. 2019. Documentation of Phosphine Resistance in Red Flour Beetle, Tribolium castaneum Herbst (Tenebrionidae, Coleoptera) and Rice Weevil, Sitophilus oryzae Linn (Curculionidae, Coleoptera) in Tamil Nadu, India. Int.J.Curr.Microbiol.App.Sci. 8(02): 1426-1433. doi: https://doi.org/10.20546/ijcmas.2019.802.166 